Uludag Univ. J. Fac. Vet. Med.

33 (2014), 1,2: 21-26

\title{
Balarılarında Varroa destructor Enfestasyonuna Karşı Pudra Şekeri Etkinliğinin Araştırılması
}

\author{
Mustafa Necati MUZ ${ }^{1} \quad$ Servet ARSLAN ${ }^{2} \quad$ Ahmet Onur GIRISGGIN ${ }^{3}$
}

Geliş Tarihi: 14.10 .2014

Kabul Tarihi: 30.10.2014

\begin{abstract}
Özet: $\mathrm{Bu}$ araştırma Varroa destructor ile organik mücadele amacıyla kullanılan pudra şekeri uygulamasının Nisan ve Haziran aylarının sabah ve öğleden sonra saatlerindeki etkinliğinin belirlenmesi amacıyla yapılmıştır. Çalışma Hatay'a bağlı Arsuz yöresinde yedi farklı arılıkta yürütülmüştür. Her arılıkta Varroa destructor ile yüksek düzeyde enfeste olduğu belirlenen onar adet koloni deneme amacıyla, beşer adet koloni kontrol amacıyla toplam 105 adet koloni kullanılmıştır.. Deneme grubuna farklı aylar ve saatlerde aynı miktarda pudra şekeri uygulanmıştır. Denemelerin öncesi ve sonrasında $V$. destructor sayımları gerçekleştirilmiştir.

Pudra şekeri uygulamasının etkinliği, tedaviden önce ve sonra arıların üzerindeki akar yükü farklılı̆ıını değerlendiren Henderson-Tilton formülü uygulanarak sabah ortalama \% 39,72 öğleden sonra ortalama \% 44,26 olarak belirlenmiş̧ir. Karşılaştırılan bu iki etkinlik düzeyi arasında anlamlı bir fark bulunmamıştır $(\mathrm{p}<0,05)$. Varroa destructor enfestasyonu ile nektar akımı dönemlerinde mücadele edilmesi gereken durumlarda kalıntı ve direnç riski taşımayan pudra şekeri uygulaması organik mücadeleye katkı sağlamaktadır.
\end{abstract}

Anahtar Kelimeler: Varroa destructor, organik mücadele, pudra şekeri, etkinlik, koloni kaybı

\section{Survey of the Effectiveness of Powdered Sugar Dusting Against Varroa destructor Infestation of Honeybees.}

\begin{abstract}
This study was carried to determine the efficacy of organic powdered sugar dusting method against to Varroa destructor parasitism in the morning and afternoon hours on April and July. This study was conducted in seven different apiaries located on the province of Hatay - Arsuz. In the each of the apiaries highly V. destructor infested ten experimental colonies and five control colonies were used as totally 105 colonies. Same treatment procedure was done to all trial groups in different months and hours of days. Fallen mites were counted before and after trials. Efficacy of powdered sugar dusting method was determined by Henderson-Tilton formula application as $39,72 \%$ on the morning trial and $44,26 \%$ on the afternoon trial by distinguishing the mite loads on honeybees. There is not a significant importance between two compared groups at level of $p<0.05$. The powdered sugar dusting can be used as a supporting and organic struggle method for Varroasis during the nectar flow periods against to residue problems and the risk of drug resistances.
\end{abstract}

Key Words: Varroa destructor, organic struggle, powdered sugar, efficiency, colony losses.

Namık Kemal Üniversitesi, Veteriner Fakültesi, Parazitoloji Anabilim Dalı, 59030, Tekirdağ, Türkiye, mustafamuz@nku.edu.tr

2 Akdeniz Üniversitesi, Teknik Bilimler Meslek Yüksek Okulu, Doğa ve Çevre Bölünü, 07070, Antalya, Türkiye,

3 Uludağ Üniversitesi, Veteriner Fakültesi, Parazitoloji Anabilim Dalı, 16128, Bursa, Türkiye. 


\section{Giriş}

Bal arıları (Apis mellifera) dünyada ticari açıdan yetiştiriciliği yapılan en değerli böcek türüdür. Bal arılarının ekonomik önemi bitkisel üretime sağladıkları verim artışı ve gıda - ilaç sanayisinde kullanılan bal ile diğer arı ürünleri yoluyla olmaktadır. Bal arısı kolonileri bazı ülkelerde doğal tozlaşma ve bitkisel üretimde verim artışı amacıyla kiralanmaktadır. Türkiye gibi ülkelerde yapılan göçer arıcılık ise endemik bitki çeşitliliğinin sürdürülmesine ve ekolojik dengenin korunmasına eşsiz katkı sağlamakta$\mathrm{d}_{1} \mathrm{r}^{1,18,21,22,27}$

Koloni sağllğ açısından hayati önemi olan patojenler arasinda ön sıralarda yer alan Varroa destructor dünyanın farklı yerlerine yayılmıs durumdadır. Varrroa destructor erginleri sadece bal arısı üzerinde bulunan, kolonilerde verim ve yaşam kayıplarına neden olan bir dış parazittir. Varroa destructor ve bal arıları kolonideki yavru gözlerini ortak kullanırlar ${ }^{26}$. Bal arısı pupalarının vücut sıvılarını emerken bazı virüsleri de nakleden $V$. destructor kış salkımının oluşamaması ya da erken sonlanmasına neden olabilir ${ }^{19,20}$. Parazite karş1 üretilen inorganik sentetik kimyasal ilaçların yanında pudra şekeri gibi doğal ürünler de kullanılmaktadır. Ancak mücadelede kullanılan ilaçların bal ve diğer arı ürünlerinde kalıntı bırakması ciddi sağlık riski oluşturur ve arı ürünlerinin değerini düşürür ${ }^{2,17}$.

Arn kolonilerinden ticari beklentiler arttıkça kolonilerin hastalıklara karşı direnci azalmaktadır. Bu nedenle doğal arıcılığa geri dönüş sürecini başlatan ekolojik arıcılığa eğilimin artması hastalıklara karşı doğal koruma ve tedavide organik ürünlerin kullanılmasını beraberinde getirmiştir. Doğal üretime olan talebin artması arı yetiștiricilerini alternatif organik tedavi metotlarını araștırmaya yönlendirmektedir. Üreticiler gerektiğinde nektar akımı döneminde bile kalıntı bırakmadan kullanabilecekleri doğal ürünlere ihtiyaç duymaktadırlar, ${ }^{2,15,16,26}$.

$\mathrm{Bu}$ araştırma, Doğu Akdeniz'de narenciye nektarı akımı döneminde Varroasise karşı kullanılabilecek doğal mücadele seçenekleri arasında gösterilen pudra şekeri uygulamasının, üretici koşullarındaki etkinliğinin Nisan ve Haziran aylarında günün farklı saatlerinde test edilmesi amacıyla gerçekleştirilmiştir.

\section{Materyal ve Metod}

Çalışma, Hatay'ın İskenderun ilçesine bağlı Arsuz beldesinde kışlatma amaciyla bulunan yedi farkl1 arılikta 11/11/2012 tarihinde başlatılmıştır. Varroasis mücadelesi amacıyla kullanılan pudra şekerinin yöredeki tedavi etkinliği, farklı mevsimlerde ve günün değişik zamanlarında mukayeseli olarak araştırılmıştır. $\mathrm{Bu}$ amaçla yapılan denemelerde yedi çerçeve arılı koloniler arasında akar ile enfestasyon oranı en yüksek olanlar kullanılmıştır. Bu amaçla çalışmanın başlangıç tarihinde kolonilerin en dış çerçevelerinden iki yüzer adet ergin işçi arı, deterjanlı su dolu kap içerisine silkelendikten sonra beş dakika çalkalanarak akarların dökülmesini takiben sayımları yapılmıştır ${ }^{11}$. Her arılikta akar ile en yüksek düzeyde enfeste olan onar adet koloni yani toplam yetmiş adet koloni bu şekilde belirlenmiştir. Varroa mücadelesi başlatılana kadar bu kovanlara her hangi bir uygulama yapılmamış ve akar enfestasyon yüzdesi literatürde belirtilen formüle göre hesaplanmıştır ${ }^{10}$.

Kontrol grubu olarak yedi farklı arılıktan beşer adet yani toplam otuz beş adet koloni rasgele seçilmiştir. Bu kolonilere her hangi bir ilaçlama yapılmamıştır. Çalışmada kullanılan tüm kolonilerin akar enfestasyonları pudra şekeri uygulanmadan bir gün önce yani 01/04/2013 ve 01/06/2013 tarihleri ile şeker uygulandıktan bir gün sonra yani 03/04/2013 ve 03/06/20313 tarihlerinde deterjanlı su metoduna göre tekrar belirlenmiştir.

Uygulama amaciyla kullanılan pudra şekeri paketlenmiş hazır ticari ürün şeklinde satın alınmıştır. Pudra şekeri kullanımdan bir gün önce çerçeve başına 25 gram olacak şekilde tartılarak (ör: 25 gr x 7 çerçeve= 175 gr) topaklanmaması için beş gram baklavalık ticari buğday unu ile katılarak, Premier marka ev-tipi elektrikli kahve öğütücüsünde beș defa birer dakika süre ile homojen hale getirilmiş ve paketlenmiştir.

Pudra şekerinin günün farklı saatlerindeki etkinliğini belirlemek amaciyla Nisan ve Haziran aylarında, her bir arllikta sabah saat 10:30 11:30 arasında ilk beş koloniye, öğlenden sonra saat 15:00 - 16:00 arasında ise diğer beş koloniye uygulama yapılmıştır. Pudra şekeri elek yardımılla çerçeveler üzerine serpiştirildikten sonra kuru firça yardımıyla çerçevelerin arasına süpürülmüştür. Kontrol gruplarına her hangi bir 
uygulama yapılmamıştır. Kovan kontrolleri ertesi gün yapılarak arılar üzerindeki $V$. destructor yükü tedaviden önce ve sonra deterjanlı su metoduna göre sayılarak pudra şekerinin etkinliği bu tip çalışmalarda kabul gören Henderson -Tilton formülüne göre tespit edilmiştir ${ }^{10}$.

Nisan ayının ilk haftası uygulama yapılan deneme ve kontrol grupları Haziran ay1 uygulamasına kadar arılıklarda sabit olarak tutulmustur. Uygulamalardan birer hafta sonra ana arı kontrolleri yapılmıştır. Deneme amacıyla ayrılan tüm koloniler oğul vermemesi için çalışma sonuna kadar kontrol altında tutulmuştur.

\section{Bulgular}

Denemelerden önce ve sonra Nisan ve Haziran aylarında arılar üzerindeki akar yüküne uygulanan Henderson-Tilton formülüne göre bu etki sabah 10:30 - 11:30 saatlerinde ortalama \% 39,72, öğleden sonra 15:00 - 16:00 saatlerinde ise ortalama \% 44,26 olarak tespit edilmiştir (Tablo 1, 2, 3). Bu değerlere yapılan istatistiki analiz sonucunda etkinlik bakımından sabah ve öğleden sonra grubu arasında anlamlı bir farkl1lik bulunmamıştır $(\mathrm{p}<0,05)$. Çalışma sonuçlarına göre pudra şekeri uygulaması Nisan ayında, Haziran ayına göre daha az etkinliğe sahiptir. Nisan ayının sabah uygulamasında öğleden sonra uygulamasına göre daha az sayıda akar döküldüğü tespit edilmiştir. Haziran ayının sabah uygulamasında ise öğleden sonra uygulamasına göre daha fazla sayıda akar döküldügü tespit edilmiştir. Ancak günün farklı saatlerindeki akar sayımları arasında önemli bir fark olmadığ 1 tespit edilmiştir $(\mathrm{p}<0,05)$. Hatay ilinin Arsuz yöresinde yapılan bu çalışmaya göre, Nisan ve Haziranda aylarındaki $V$. destructor mücadelesi için pudra şekeri uygulamasının yapılması önerilebilir. Uygulamanın yapıldığ 1 saatler arasında ölerek kovan önüne çıkarılan arıya rastlanmamıştır. Kovan içerisindeki arılar üzerlerine dökülen pudra şekerini temizlemişlerdir. Pudra şekeri uygulamasının olumsuz etkisi gözlenmemiștir.
Tablo 1: Nisan ve Haziran Aylarında, Saat 10:30 - 11:30 arası deneme sonuçları

Table 1: Result of the trials in April and June between 10:30 - 11:30 a.m

\begin{tabular}{|c|c|c|c|c|}
\hline \multicolumn{5}{|c|}{ Pudra Şekeri 10:30 - 11:30 saatleri Deneme Grubu } \\
\hline Tarih & 06.04 .13 & 08.04 .13 & 01.06 .13 & 03.06 .13 \\
\hline \multicolumn{5}{|c|}{ Ortalama Varroa Sayıları } \\
\hline 1. Arılık & 85 & 53 & 96 & 56 \\
\hline 2. Arılık & 79 & 47 & 88 & 50 \\
\hline 3. Arılık & 80 & 49 & 89 & 50 \\
\hline 4. Arılık & 92 & 59 & 95 & 56 \\
\hline 5. Arılık & 88 & 55 & 90 & 52 \\
\hline 6. Arılık & 89 & 57 & 91 & 51 \\
\hline 7. Arılık & 93 & 52 & 95 & 59 \\
\hline Ortalama Toplam & 86,57 & 53,14 & 92,0 & 53,42 \\
\hline \multicolumn{5}{|c|}{ Kontrol Grubu } \\
\hline Tarih & 06.04 .13 & 08.04 .13 & 01.06.13 & 03.06 .13 \\
\hline \multicolumn{5}{|c|}{ Ortalama Varroa Sayıları } \\
\hline 1. Arılık & 77 & 79 & 105 & 100 \\
\hline 2. Arılık & 81 & 80 & 108 & 105 \\
\hline 3. Arılık & 81 & 81 & 98 & 99 \\
\hline 4. Arılık & 69 & 67 & 86 & 83 \\
\hline 5. Arılık & 95 & 96 & 102 & 96 \\
\hline 6. Arılık & 91 & 93 & 96 & 97 \\
\hline 7. Arlık & 88 & 89 & 101 & 99 \\
\hline Ortalama Toplam & 83,14 & 83,57 & 99,42 & 97,0 \\
\hline
\end{tabular}

Tablo 2: Nisan ve Haziran Aylarında, Saat 15:00 - 16:00 arası deneme sonuçları

Table 2: Result of the trials in April and June between 15:00 - 16:00 a.m

\begin{tabular}{|c|c|c|c|c|}
\hline \multicolumn{5}{|c|}{ Pudra Şekeri 15:00 - 16:00 saatleri Deneme Grubu } \\
\hline Tarih & 06.04.13 & 08.04.13 & 01.06 .13 & 03.06 .13 \\
\hline \multicolumn{5}{|c|}{ Ortalama Varroa Sayıları } \\
\hline 1. Arılık & 79 & 45 & 86 & 41 \\
\hline 2. Arılık & 91 & 51 & 96 & 43 \\
\hline 3. Arılık & 86 & 59 & 91 & 40 \\
\hline 4. Arılık & 65 & 39 & 79 & 39 \\
\hline 5. Arılık & 93 & 56 & 109 & 56 \\
\hline 6. Arılık & 90 & 53 & 101 & 52 \\
\hline 7. Arılık & 83 & 48 & 97 & 49 \\
\hline Ortalama Toplam & 83,85 & 50,14 & 94,14 & 47,71 \\
\hline \multicolumn{5}{|c|}{ Kontrol Grubu } \\
\hline Tarih & 06.04 .13 & 08.04 .13 & 01.06 .13 & 03.06 .13 \\
\hline \multicolumn{5}{|c|}{ Ortalama Varroa Sayıları } \\
\hline 1. Arılık & 77 & 79 & 105 & 100 \\
\hline 2. Arılık & 81 & 80 & 108 & 105 \\
\hline 3. Arılık & 81 & 81 & 98 & 99 \\
\hline 4. Arılık & 69 & 67 & 86 & 83 \\
\hline 5. Arılık & 95 & 96 & 102 & 96 \\
\hline 6. Arılık & 91 & 93 & 96 & 97 \\
\hline 7. Arılık & 88 & 89 & 101 & 99 \\
\hline Ortalama Toplam & 83,14 & 83,57 & 99,42 & 97,0 \\
\hline
\end{tabular}


Tablo 3: Nisan ve Haziran Aylarında, Farklı Saatlerde Pudra Şekeri Uygulaması Etkinliği

Table 3: Efficiacy of Powdered sugar in different hours of the April and June

\begin{tabular}{|c|c|c|c|}
\hline \multicolumn{4}{|c|}{ Pudra Şekeri Uygulaması Etkinliği \% } \\
\hline Deneme & $\begin{array}{l}\text { 10:30-11:30 } \\
\text { saatlerinde }\end{array}$ & $\begin{array}{l}\text { 15:00-16:00 } \\
\text { saatlerinde }\end{array}$ & Etkinlik \% \\
\hline $\begin{array}{l}\text { Nisan } \\
\text { ayı }\end{array}$ & $\% 38,93$ & $\% 40,51$ & $\% 39,72$ \\
\hline $\begin{array}{l}\text { Haziran } \\
\text { ayı }\end{array}$ & $\% 40,48$ & $\% 48,05$ & $\% 44,26$ \\
\hline
\end{tabular}

\section{Tartışma ve Sonuç}

Pudra şekerinin kovan içine uygun dönemlerde ve yeterli miktarda uygulanması, $V$. destructor yükünü doğal șekilde azaltmak için alternatif olabilirr ${ }^{4}$. Söz konusu uygulama ile çok küçük toz zerrecikleri haline dönüştürülen pudra şekeri, Varroanın tırnak ucunda bulunan ambulacrum adı verilen tutunma organellerini kaplayarak akarın arıların üzerinden kayıp düşmesine neden olmakta, ayrica akarın oksijen almak üzere özelleşmiş hava deliklerine girerek nemlenir ve akar1 oksijensiz bırakır ${ }^{5-7}$. Bu etkiyi gözleyebilmek için pudra şekeri uygulamasının yapıldığı dönemde çevre sıcaklığının fazla ve nemin az olması teknik açıdan önemlidir. Pudra şekerinin yeterince iyi ögütülmüş olması ve tozuması, şeker partiküllerinin akarın ambulacrum ve trachea girişlerini kapatması beklenen etkinin gözlenmesi için önemlidir ${ }^{3,7}$. Pudra şekerinin kullanılması konusunda benzer araştırmalar bulunmakla birlikte değişik mevsimlerde ve günün farklı saatlerinde yapılan az sayıda araştırmaya rastlanmıştır ${ }^{23,24}$.

Bal arısı kolonilerinde $V$. destructor ile bulaşıklık oranını belirlemek amacıyla kovan dışına alınan arılarda kullanılan eter-alkol, pudra şekeri, deterjanlı su metodu gibi teknikler arasında kovan içerisine de uygulanarak tedavi amaçlı kullanılabilecek tek metot pudra şekeri uygulamasıdır. Marketlerde ambalajlı olarak satılan pudra şekeri, sofralık çay şekeri olarak tabir edilen kristal toz şekerin ögütülmüş halidir. Bu araştırmadaki metot, pudra şekerinin çok iyi ögütülmüş olmasını ve kovan içine uygulama esnasında dış çevre şartlarının şekerin tozumasına elverişli olmasını gerektirir. $\mathrm{Bu}$ araştırmada kullanılan pudra şekerinin partikül büyüklügünün nanometre düzeyinde ölçümü, sadece ileri düzey laboratuarlarda yapılabileceği, partiküllerin saha şartlarındaki nemden etkilenerek stabil kalamayacağı ve son kullanıcılar açısın- dan pratik öneme sahip olmaması nedeniyle gerekli görülmemiştir. Bu uygulamanın çevre sıcaklığının yüksek, nem seviyesinin olabildiğince düşük olduğu yörelerde, uygun mevsim ve saatlerde yapılması önerilmektedir

$\mathrm{Bu}$ araştırmada diş sıcaklık ve nem değerlerinin farklı olduğu aylarda yapılan uygulamaların sonuçları farklı bulunmuştur. Nisan ayında çevre sıcaklığ 1 düşük ve nem oran fazla ancak pudra şekeri uygulamasının etkinliği düşüktür. Haziran ayında ise çevre sıcaklığı yüksek ve nem oranı düşük ancak pudra şekerinin etkinliği daha fazladır. Sabah ve öğleden sonra uygulamaları arasında her iki mevsimde de çok önemli bir farkl111k gözlenmemiştir. Bu uygulama, etkinliğin artması ve varroa seviyesinin iyice düşürülmesi için gerektiğinde haftada iki defa tekrarlanabilir.

Varroa destructor bulaşıklığına karşı sentetik kimyasal ilaçların (ör: amitraz, flumethrine, fluvalinate, coumaphos) kullanımı yerine alternatif doğal ürünlerin tercih edilmesi dünya genelinde yapılan araştırmalar ile bilimsel olarak desteklenmektedir ${ }^{8,12,25}$. Özellikle profesyonel arıcılar, kolonilerin varroa mücadelesini geç sonbaharda tamamlayarak kışlatma dönemini çok düşük düzeyde ya da akardan ari olarak atlatmalıdir. Ancak bu kural her zaman uygulanamamaktadır. $\mathrm{Bu}$ durumda ana nektar akımı süresince kolonilerin yeterli miktarda bal üretimi gerçekleştirebilmesi için en az 45 gün önce planlanacak Varroa mücadelesi önem taşımaktadır. İlkbaharda günlük yumurta ve sırlanmamış yavru gözlerinin aşırı düzeyde bulunduğu kolonilere özellikle piretroit gurubu kimyasal ilaçların ya da ruhsatsız organik asit türevi maddelerin uygulanması hayati sakıncalar doğurabilir. $\mathrm{Bu}$ gibi ilaçlar genellikle ergin arıların metabolizma hızları hesap edilerek üretilmekte olup arıcılar kimyasal ilacı uygulanması gereken doz ve sürede kullanamadıkları takdirde gözlerden yeni çıkan yavrularda ilaca karşı intolerans ve genç koloni nüfusunda gerilemeye neden olmaktadırlar. Bu durumda nektar döneminde ihtiyaç duyulan farklı yaş dönemlerindeki arı nüfusuna yeterli düzeyde ulaşılamamakta ve koloni yönetimi hataları ortaya çıkmaya başlamaktadır. Üreticilerin 'arım var ama balım yok' diyerek yakındıkları bu durumun önemli sebeplerinden birisi doğru ilacin doğru zaman ve sürede kullanılmamasından kaynaklanan koloni yönetimi problemleridir.

Benzer olarak kolonilerin davranış fizyolojisini olumsuz etkileyen piretroit türevi kim- 
yasal ilaçların ve timol gibi baskın koku oluşturan ilaçların arıların hijyen davranışını baskılayacağ 1 ve kovan içi patojenlerin tehlikeli duruma geçebileceği unutulmamalıdır. Varroasise karşı ilaçlama yapılmadan önce kolonilerin özellikle yavru dönemi açısından gözden geçirilerek, arılığına en uygun, organik mücadele metodunun tercih edilmesi gerekmektedir ${ }^{9,13,14}$. Sentetik kimyasal ilaç kalıntılarının tekrarlanan uygulamalara bağlı olarak kovan içinde birikebileceği, özellikle larva ve genç arılar için toksik, ergin arılar için ise davranış fizyolojisi ve bağışıklık sisteminin yanıtını bozacak kümülatif etkilere neden olabileceği dikkate alınmalıdır.

Sonuç olarak balarılarında bulunan $V$. destructor akarına karşı pudra șekeri uygulamas1 periyodik şekilde ve destekleyici tedavi olarak başarıyla uygulanabilir. Yöntemin arılar üzerinde olumsuz bir etkisinin olmaması, ar ürünlerinde herhangi bir kalıntı bırakmaması, mekanik olarak etkisini gösterdiği için akarların direnç geliştirememesi gibi çeşitli avantajları nedeniyle, diğer kimyasal ilaçların aksine nektar akımı zamanında da kullanılabilecektir. Üretici ve araştırıcıların yaptıkları tüm çalışmalarda mutlaka sağl1klı arılar kullanarak başarı elde edebileceği unutulmamalıdır.

\section{Kaynaklar}

1. Allsopp M.H., de Lange WJ, Veldtman R., 2008. Valuing insect pollination services with cost of replacement. PLoS One, 10,3- 9.

2. Aydın L., 2005. Varroa destructor kontrolünde yeni stratejiler. U Arıcılık Derg., 5,59-62.

3. Çakmak İ., Çakmak S., Fuchs S., Yeninar H., 2011. Bal arısı kolonilerinde varroa bulaşıklık seviyesinin belirlenmesinde pudra şekeri ve deterjan yöntemlerinin karşılaştırılması. U Arıcılık Derg., 11,63-68.

4. Ellis A.M., Hayes G.W., Ellis J.D., 2009. The efficacy of dusting honey bee colonies with powdered sugar to reduce varroa mite populations. J Apicultural Res and Bee World, 48,72-76.

5. Fakhimzadeh K., 2000. Potential of super-fine ground, plain white sugar dusting as an ecological tool for the control of varroasis in the honey bee (Apis mellifera). American Bee J., 140,487491.

6. Fakhimzadeh K., 2001a. The effects of powdered sugar varroa control treatments on Apis mellifera colony development. J Apicultural Res, 40,105109.

7. Fakhimzadeh K., 2001b. Effectiveness of confectioner sugar dusting to knock down Varroa dest- ructor from adult honey bees in laboratory trials. Apidologie, 32,139-148.

8. Girisgin A.O., Aydın L., 2010. Efficacies of formic, oxalic and lactic acids against Varroa destructor in naturally infested honeybee (Apis mellifera L.) colonies in Turkey. Kafkas Univ Vet Fak Derg, 16,941-945.

9. Harbo J.R., 2000. Heating adult honey bees to remove Varroa jacobsoni. J Apicultural Res., 39,181-183.

10. Henderson C.F., Tilton E.W., 1955. Tests with acaricides against the brown wheat mite. $J$ Econ Entomol., 48,157-161.

11. Kar S., Kaya N., Güven E., Karaer Z., 2006. Yeni geliştirilen tespit kabı ile ergin arılarda Varroa enfestasyonunun belirlenmesi. U Arlcllık Derg., 6,68-73.

12. Kütükoglu F., Girisgin A.O., Aydin L., 2012. Varroacidal efficacies of essential oils extracted from Lavandula officinalis, Foeniculum vulgare, and Laurus nobilis in naturally infested honeybee (Apis mellifera L.) colonies. Turk J Vet Anim Sci., 36,554-559.

13. Le Conte Y., Colin M.E., Paris A., Crauser D., 1998. Oil Spraying as a potential control of Varroa jacobsoni. J Apicultural Res., 37,291-293.

14. Macedo P.A., Wu J., Ellis M.D., 2002. Using inert dusts to detect and assess varroa infestations in honey bee colonies. J Apicultural Res., 40,3-7.

15. Mert G., Yücel B., Kösoğlu M., 2007a. Bal arıs1 hastalık ve zararlıları ile organik mücadele yöntemleri (I). Hasad, 261,62-64,

16. Mert G., Yücel B., Kösoğlu M., 2007b. Bal arıs1 hastalık ve zararlıları ile organik mücadele yöntemlerim (II). Hasad, 263,52-58.

17. Mert G., Yücel B., 2011. The efficiency levels of organic acids used for varroa (Varroa jacobsoni) control in honey bee (Apis mellifera L.) colonies and their effects on colony development. J Anim Vet Advan., 10,1106-1111.

18. Muz M.N., 2008. Bal arılarında ani koloni sönmesi. T Parazitoloji Derg, 32,271-275.

19. Muz D., Muz M.N., 2009. Survey of the occurrence of Deformed Wing Virus and multiple parasites of queens (Apis mellifera L.) in apiaries with collapsed colonies in Hatay, Turkey. J. Apicultural Res and Bee World, 48,204-208.

20. Muz M.N., Solmaz H, Yaman M, Karakavuk M, 2012. Kış Salkımı Erken Bozulan Arı Kolonilerinde Paraziter ve Bakteriyel Patojenler. YYU Vet Fak Derg., 23,147 - 150.

21. Nicholls C.I., Altieri M.A., 2013. Plant biodiversity enhances bees and other insect pollinators in agroecosystems. Agronomy for Sustainable Development, 33,257-274. 
22. Ollerton J., Price V., Armbruster W.S., Memmott J., Watts S., Waser N.M., Totland O., Goulson D., Alarcón R., Stout J.C., Tarrant S., 2012. Overplaying the role of honey bees as pollinators: a comment on Aebi and Neumann. Trends Ecol, 27,141-142.

23. Paliano N., Ellis M.D., 2005a. Strategy for using powdered sugar to reduce varroa populations in honey bee colonies. J Apicultural Res., 44,54-57.

24. Paliano N., Ellis M.D., 2005b. Only large amounts of powdered sugar applied directly to brood cells harms immature honey bees. J Apicultural Res., 44,33-35.
25. Yücel B., Duran G., 2004. Varroa (Varroa jacobsoni Q.) ile mücadelede organik asitlerin ve bitkisel maddelerin kullanımı. Hasad, 2,22-25.

26. Yücel B., 2005. Bal arıs1 (Apis mellifera L.) kolonilerinde varroa (Varroa jacobsoni Q.) ile mücadelede farklı organik asitlerin kullanılmasının koloni performansı üzerine etkileri. Hayvansal Üretim, 46,33-39.

27. Winfree R., Gross B.J., Kremen C., 2011. Valuing pollination services to agriculture. Ecological Economics, 75,80-88. 